\title{
Heart Rate Variability in Children Following Drowning Injury
}

\author{
Madhuradhar Chegondi ${ }^{1,2}$, Jun Sasaki ${ }^{3,4}$, Sayed Naqvi ${ }^{3,4}$, Wei-Chiang Lin ${ }^{5}$, Andre Raszynski3i,4, Balagangadhar R. Totapally ${ }^{3,4,5}$ \\ ${ }^{1}$ Division of Critical Care Medicine, Nemours Children's Hospital, ${ }^{2}$ Department of Pediatrics, University of Central Florida College of Medicine, Orlando, ${ }^{3}$ Division \\ of Critical Care Medicine, Nicklaus Children's Hospital, “Department of Pediatrics, Herberth Wertheim College of Medicine, Nicklaus Children's Hospital, Florida \\ International University, ${ }^{5}$ Department of Biomedical Engineering, Florida International University, Miami, FL, USA
}

\section{Abstract}

Heart rate variability (HRV) has been used as prognostic tool in various disorders in pediatric and adult patients. In our study we aimed to evaluate heart rate variability indices and their association with neurological outcome in three children with anoxic brain injury following drowning. Three children included in the study were admitted following drowning and required mechanical ventilation and targeted temperature management. All physiologic data, including electrocardiography (ECG) and EEG were collected for a period of 3-5 days after enrollment. ECG signals were analyzed in both time and frequency domains. The spectral power of the low-frequency (LF) band (0.04-0.15 Hz) and that of the high-frequency (HF) band $(0.15-0.4 \mathrm{~Hz})$, the standard deviation of the average R to R ECG intervals (SDANN) were calculated. Mean low-frequency/high-frequency power ratios (LF/HF) were compared using a two-tailed $t$-test and ANOVA with Tukey-Kramer multiple comparisons. The power in the LF band, the LF/HF power ratio, and the SDANN, were lower in children who had a poor outcome, and during periods of isoelectric or burst suppression EEG patterns.

Keywords: Children, drowning, heart rate variability

\section{INTRODUCTION}

Heart rate variability is defined as oscillation of the interval between consecutive heartbeats. ${ }^{[1]}$ The autonomic nervous system controls the cardiovascular system through afferent and efferent nerve connections to the heart. ${ }^{[2]}$ The net effect of the autonomic nervous system on the heart depends on multiple factors, including feedback from baroreceptors and chemoreceptors, respiratory variation, and activity of the vasomotor and thermoregulatory systems. ${ }^{[3]}$ Predominant sympathetic activity results in an increased heart rate while a higher parasympathetic activity causes a decreased heart rate. Heart rate variability is an indication of the heart's ability to respond to changes in intrinsic and extrinsic stimuli. Various physiological conditions, such as physical exercise, hypoxia, and drowning, can affect autonomic activity. Publication of a study of heart rate variability during fetal distress resulted in an increased interest in the mechanism of heart rate variability and its clinical applicability in ill children. ${ }^{[4]}$

Different heart rate variability patterns have been identified as early sensitive markers for outcome in various diseases. Increased heart rate variability is an index of an efficient autonomic nervous system, with good adaptation to

\begin{tabular}{|l|l|}
\hline \multicolumn{3}{|c|}{ Access this article online } \\
\hline Quick Response Code: & Website: \\
\hline & www.ijccm.org \\
\cline { 2 - 2 } & \\
\hline
\end{tabular}

multiple stimuli, whereas low heart rate variability indicates inadequately adapted autonomic nervous system and is a sign of diseased states. ${ }^{[5]}$ Advances in computational power led to research on heart rate variability in various disorders, especially in cardiovascular disease in adults. However, there are limited data on the reproducibility of heart rate variability in children. ${ }^{[6]}$ The present study evaluates various indices of heart rate variability, a surrogate of autonomic nervous system imbalance, in three patients with anoxic brain injury after a drowning episode.

\section{Case History and Analysis}

The study includes three children who were a part of multimodal neuromonitoring in critically ill children funded by the Department of Defense (Award\# W81XWH-09-1-0295). The first patient died after meeting brain death criteria, the second

Address for correspondence: Dr. Balagangadhar R. Totapally,
Division of Critical Care Medicine, Nicklaus Children's Hospital,
3100 SW 62
E-mail: bala.totapally@mch.com

This is an open access article distributed under the terms of the Creative Commons Attribution-NonCommercial-ShareAlike 3.0 License, which allows others to remix, tweak, and build upon the work non-commercially, as long as the author is credited and the new creations are licensed under the identical terms.

For reprints contact: reprints@medknow.com

How to cite this article: Chegondi M, Sasaki J, Naqvi S, Lin WC, Raszynski A, Totapally BR. Heart rate variability in children following drowning injury. Indian J Crit Care Med 2018;22:53-5. 
patient had a complete recovery, and the third patient survived with severe neurologic dysfunction. These children were admitted with acute brain injury from submersion to Pediatric Intensive Care Unit and received mechanical ventilation and therapeutic hypothermia. Electrocardiography (ECG) signals exported from the central monitor were analyzed in both time and frequency domains. Each hour, ECG data were split into twelve 5-min segments (a total of $8 \mathrm{~h}$ of data from each patient). We have calculated the mean NN interval (R-to-R interval) for each of the 12 segments. Then, the standard deviation of $\mathrm{NN}$ means in 12 segments (SDANN) was calculated and used in statistical analysis. The data in the frequency domain were analyzed with the Lomb periodogram for power at low-frequency (LF) band (LF: $0.04-0.15 \mathrm{~Hz}$ ) and high-frequency (HF) band (HF: 0.15-0.4 Hz). The mean LF/HF ratio was calculated. $t$-Test and ANOVA with Tukey-Kramer multiple comparisons were used to analyze the data.

The mean LF/HF ratios for all hours were $0.11,0.94$, and 0.13 for three children, respectively. LF/HF ratio in the second child was significantly different from the other two children $(P<0.05)$. Child 1 and Child 3 had isoelectric or burst suppression in electroencephalogram (EEG) for few hours. Power in LF band (192 vs. 817 arbitrary units [AU]), LF/HF ratio ( 0.25 vs. 0.68$)$, and SDANN ( 13 vs. $21 \mathrm{~ms}$ ) were significantly lower during isoelectric or burst-suppression periods compared to active EEG periods $(P<0.05)$. During hypothermia, power in LF band was lower (304 vs $907 \mathrm{au}$; one way $t$-test, $P<0.05$ ) and a trend towards lower $\mathrm{LF} / \mathrm{HF}$ ratio compared, to normothermia periods. In general, the power in the HF band was not significantly influenced by EEG activity or hypothermia.

\section{DISCUSSION}

Heart rate is variable in healthy individuals, and the degree of heart rate variability correlates with a person's health status. Heart rate variability measurements are often derived from 2 to 5 min or 24 to $48 \mathrm{~h}$ of ECG recordings in the time and frequency domains ${ }^{[1]}$ Sequential hourly heart rate variability measurements may detect autonomic nervous system dysfunction more precisely than information recorded during $24-48 \mathrm{~h}$ periods or isolated short-term recordings. Power spectral analysis helps separate and quantitatively assess the rhythmic components of heart rate variability. Cardiac sympathetic and parasympathetic influences are shown to be estimated by the rhythmic LF and HF components of heart rate variability. ${ }^{[3]}$ The sympathetic mediators exert their effects for a longer time period, which is reflected in the LF power of the heart rate variability on spectral analysis (between 0.04 and $0.15 \mathrm{~Hz}$ ). The parasympathetic, vagal mediators have shorter duration influence on the heart as reflected in the HF power of the heart rate variability spectrum (between 0.15 and $0.4 \mathrm{~Hz}$ ). The resulting $\mathrm{LF} / \mathrm{HF}$ ratio indicates the sympathovagal balance. ${ }^{[7]}$

In our study, various heart rate variability indices were significantly different based on the outcome of the child's condition. Decreased power in the LF band, decreased LF/HF power ratio, and decreased heart rate variability (SDANN) were present in the two children with the worst neurologic outcomes. Similar findings were also reported in other clinical studies. ${ }^{[8]}$ Goldstein et al. found a strong negative correlation between heart rate variability and severity of brain injury, neurological outcome, and survival in children ${ }^{\left[{ }^{8]}\right.}$ In another prospective clinical study, the authors compared the autonomic cardiovascular state of children after severe brain injury and brain death and concluded a damaged sympathetic and complete interruption of the autonomic cardiovascular pathways in children with severe brain injury and brain death, respectively. ${ }^{[9]}$ These findings are comparable to our study, where Child 1 and Child 3, with poor outcomes, showed lower LF/HF ratios, whereas Child 2, with a favorable outcome, showed a high LF/HF ratio. In our study, Child 1 and Child 3 had random high LF/HF ratios during the first $4 \mathrm{~h}$ of the study, followed by a gradual decrease, which progressed to brain death and severe neurological injury, respectively. A study by Biswas et al. in children with traumatic brain injury observed an association between the LF/HF ratio and functional outcome. They found significantly lower LF/HF ratios in children who progressed to brain death and suggested this ratio as a reasonable marker to follow in children with traumatic brain injury. ${ }^{[10]}$ This phenomenon was also observed in the child 1 in this study who progressed to brain death.

Hypothermia may affect heart rate variability in the LF band; therefore, variability indices may be less useful during targeted temperature management. Our findings are comparable with other studies, suggesting an association of heart rate variability variables and clinical outcomes in children. However, this small prospective observational study included only three patients. Heart rate variability has great potential for use in continuous monitoring and as a prognostic tool in evaluating children with acute brain injury and requires further study. Heart rate is monitored in all critically ill patients, and with availability of advanced computational methods, continuous analysis of heart rate variability is now feasible.

\section{Financial support and sponsorship \\ Department of Defense (Award\# W81XWH-09-1-0295).}

\section{Conflicts of interest}

There are no conflicts of interest.

\section{References}

1. Heart rate variability: Standards of measurement, physiological interpretation and clinical use. Task Force of the European Society of Cardiology and the North American Society of Pacing and Electrophysiology. Circulation 1996;93:1043-65.

2. Aubert AE, Seps B, Beckers F. Heart rate variability in athletes. Sports Med 2003;33:889-919.

3. Brown TE, Beightol LA, Koh J, Eckberg DL. Important influence of respiration on human R-R interval power spectra is largely ignored. J Appl Physiol (1985) 1993;75:2310-7.

4. Hon EH, Lee ST. Electronic evaluation of the fetal heart rate. viii. patterns preceding fetal death, further observations. Am J Obstet Gynecol 1963;87:814-26. 
5. Pomeranz B, Macaulay RJ, Caudill MA, Kutz I, Adam D, Gordon D, et al. Assessment of autonomic function in humans by heart rate spectral analysis. Am J Physiol 1985;248(1 Pt 2):H151-3.

6. Pumprla J, Howorka K, Groves D, Chester M, Nolan J. Functional assessment of heart rate variability: Physiological basis and practical applications. Int J Cardiol 2002;84:1-14.

7. Winchell RJ, Hoyt DB. Analysis of heart-rate variability: A noninvasive predictor of death and poor outcome in patients with severe head injury. J Trauma 1997;43:927-33.
8. Goldstein B, Fiser DH, Kelly MM, Mickelsen D, Ruttimann U, Pollack MM, et al. Decomplexification in critical illness and injury: Relationship between heart rate variability, severity of illness, and outcome. Crit Care Med 1998;26:352-7.

9. Goldstein B, DeKing D, DeLong DJ, Kempski MH, Cox C, Kelly MM, et al. Autonomic cardiovascular state after severe brain injury and brain death in children. Crit Care Med 1993;21:228-33.

10. Biswas AK, Scott WA, Sommerauer JF, Luckett PM. Heart rate variability after acute traumatic brain injury in children. Crit Care Med 2000;28:3907-12. 